\title{
Logical Theatrics, or Floes on Flows
}

Translating Quine with the Shins

Joshua M. Hall

\section{CpenEdition}

\section{Journals}

Electronic version

URL: http://journals.openedition.org/ejpap/661

DOI: 10.4000/ejpap.661

ISSN: 2036-4091

Publisher

Associazione Pragma

\section{Electronic reference}

Joshua M. Hall, «Logical Theatrics, or Floes on Flows », European Journal of Pragmatism and American Philosophy [Online], VIII-2 | 2016, Online since 16 January 2017, connection on 21 April 2019. URL

http://journals.openedition.org/ejpap/661 ; DOI : 10.4000/ejpap.661

This text was automatically generated on 21 April 2019.

\section{(c) $($ ) $\odot$ (8Y NO}

Author retains copyright and grants the European Journal of Pragmatism and American Philosophy right of first publication with the work simultaneously licensed under a Creative Commons AttributionNonCommercial-NoDerivatives 4.0 International License. 


\title{
Logical Theatrics, or Floes on Flows
}

\author{
Translating Quine with the Shins
}

\author{
Joshua M. Hall
}

\begin{abstract}
"Casting ourselves thus in unreal roles, we do not generally know how much reality to hold constant.

Quandaries arise. But despite them we find ourselvesattributing beliefs, wishes, and strivings even to creatures lacking the power of speech, such

is our dramatic virtuosity." Quine
\end{abstract}

1 I will begin this comparative analysis with Quine, focusing on the front matter and first chapter of Word and Object (alongside From a Logical Point of View and two other short pieces), attempting to illuminate there a (1) basis of excessive, yet familiar, chaos, (2) method of improvised, dramatic distortion, and (3) consequent neo-Pragmatist metaphysics. Having elaborated this Quinian basis, method and metaphysics, I will then show that they can be productively translated into James Mercer's poetic lyrics for The Shins, with an emphasis on the first song, entitled "Caring is Creepy," from their debut studio album, Oh, Inverted World! Finally, I will explain why Quine and Mercer are particularly suited to this translation (in contrast to other philosophically-rich pop lyricists such as Bob Dylan, and other pragmatist philosophers like Robert Brandom), in the course of which important implications will emerge for our globalized world today. ${ }^{1}$

Before I begin, however, it might be helpful to clarify what I mean by "Pragmatist metaphysics." I would argue that there are, at most, Wittgensteinian family resemblances among the metaphysical positions adopted by philosophers who self-identify as Pragmatist. Consequently, the best one can do, arguably, is to arrange these family members around one or more family traits or characteristics. Following William Myers, I have chosen to focus on the characteristic of an emphasis on process rather than substance in metaphysics. ${ }^{2}$ Using this emphasis as the basis or axis for a spectrum of Pragmatist metaphysical views, from maximally fluid conceptions such as James' radical empiricism to rigidly solid frameworks such as Putnam's internal realism, I would suggest that Quine occupies the moderate middle position on this spectrum. 
3 More precisely, at the boundary marker on the left side of this spectrum - representing maximal substantiality - would be any metaphysical position that posits any kind of thing-like substance (whether physical, mental, or otherwise) as the sole foundation of reality to which all else reduces. Anything in that area would be too static to qualify as a pragmatist metaphysics in my sense. And at the boundary maker on the right side of this spectrum - representing maximal fluidity - would be any explicitly anti-metaphysical position (such as Heraclitus' flux), or the rejection/abandonment of the question of metaphysics altogether (such as Derrida's "closure" of metaphysics). Anything in this latter area would be insufficiently metaphysical to quality. But in between these two boundary markers, starting from the most fluid pragmatist point on this continuum, and in order of increasing static-ness (moving leftward), I would order some of the major Pragmatists and neo-Pragmatists as follows: (1) Rorty's featureless conversation, (2) James' stream of self-consciousness, (3) Dewey's qualified experience, (4) Mead's gestures, (5) Quine's posited entities, (6) Peirce's end of inquiry, (7) Putnam's internal realism, (8) and Brandom's inferential semantics, to (9) Habermas' conversation about "how things are." With this clarification of my use of the phrase "Pragmatist metaphysics" in mind, I now turn to my detailed analyses of Quine.

\section{I. [Distorted] Word and [Indeterminate] Object}

4 I will first consider the text of Word and Object, specifically the opening quote, the preface and the first chapter, the latter of which serves as a first pass over the subject matter of the text as a whole. The book opens with a quote from biologist James Grier Miller, "Ontology recapitulates philology." In other words, metaphysics repeats logic, or the discourse of beings rehearses, re-stages, re-produces (in the sense of a theater production) the love of discourse. To the question as to which came first, the event or the story - the world or art - Quine thus appears to side (via Miller) with the story and art. Thus is the stage set, the scenery in place, the actors at first position for the entirety of the book, beginning with the preface.

"Language," writes Quine (1960: ix), "is a social art." Quine the scientist, lover of logic, thus begins the introduction to his book of scientific philosophy by defining language as a kind of - not science - but art. He explicates this claim as follows: "there is no justification for collating linguistic meanings, unless in terms of men's dispositions to respond overtly to socially observable stimulations" (Quine 1960: ix). One is (only?) privy to what happens on stage - on this stage on which one sits, stands or lies listless - and these happenings are constituted by the movements of the actors' bodies (including the movements of lips, teeth, tongue, larynx, lungs, etc. for speech). If there is a behind-thescenes, and for Quine we always and continue to assume that there is, then we can say nothing intelligent about it. This idea is what I am calling a basis of excessive, yet familiar, chaos. Or, zooming out to the level of Pragmatist metaphysical systems, this basis is the ocean water that flows beneath the floe of ice-solid formal discourse.

Consequent upon this lack of a firm foundation for one's behavioral responses to the other actors' behavior, all analysis reveals itself as interpretation, criticism, and improvisation - a poetic distortion sans pre-distorted reality. Put differently, every act of interpretation constitutes a translation (not attempted, for there are no attempts at translation, just good or bad translations) of (observable) behavior into (analytical) behavior, of theory-bound praxis into practically-bent theory. This includes translating 
another actor's sonic emissions into a meaningful speech pattern (or, with George Herbert Mead, one's own movement into a meaningful gesture). As an actor, one merely behaves; as an observer of other actors (including observing oneself qua actor), one creates, improvising theories to explain their behavior. This method, based on the excessive yet familiar chaos, is what I am calling improvised, dramatic distortion. Or, at the level of Pragmatist metaphysical system, this method is the ability of the ice floe to float in any direction whatsoever on its flowing basis.

7 Referring back to this flowing, chaotic basis underneath his method, Quine (1960: ix) notes that, "the enterprise of translation is found to be involved in a certain systematic indeterminacy." Note that the last two words, as a phrase, amount to an oxymoron, because it is generally agreed that (a) what it is to be a system is to be determinate, and (b) to be systematic is to have thoroughly elaborated a collection of principles, rules, positions, axioms, etc. Translation for Quine, however, is not only an indeterminate business, it is fundamentally, pervasively, even systematically indeterminate. For Quine, it is essential to the structure of translation, because essential to the structure of that which is translated, that it lacks any essential structure.

In light of these insights from Quine's Preface, one could legitimately reformulate the opening quote from Miller as follows: ontology recapitulates an abyssal indeterminacy shot through with improvised lines of translation. To summarize, (a) all that exists mirrors the flimsy structure of language; (b) reality, like language, is essentially chaotic and only secondarily, semi-arbitrarily ordered; (c) the world presents itself as undetermined, excessive and vulnerable to creative renderings; and (d) these creative renderings, which are parts acted out on the stage, since they have, quite literally, no basis "to speak of," are nothing other than that world itself; therefore (e) in actuality, there are no poetic variations of a prosaic substructure - there are only poetic originals.

9 At this point, I would like to return to my opening quote from Quine. Its original context is a discussion of what is, for Quite, the seemingly inevitability fictive and imaginary nature of propositional attitudes, but it can also be applied to the broader issues that I have been considering:

Casting our real selves thus in unreal roles, we do not generally know how much reality to hold constant. Quandaries arise. But despite them we find ourselves attributing beliefs, wishes, and strivings even to creatures lacking the power of speech, such is our dramatic virtuosity. (Quine 1960: 219)

10 With the phrases "real selves" and "unreal roles," Quine is referring to his position that propositional attitudes are simply the projection by a speaker of what $\mathrm{s} / \mathrm{he}$ imagines $\mathrm{s} / \mathrm{he}$ would feel in response to a certain stimulus, onto a third person who has just experienced that stimulus. For present purposes, however, I wish to focus on the last phrase in the quote, "our dramatic virtuosity," which I take to be central in Chapter One of Word and Object (to which I will proceed shortly). But first, it may be helpful to pause a moment here and consider Quine's analysis of translation in Chapter Two of this book.

11 The first point I wish to make here is that Quine offers us a scientist - because the linguist is an anthropologist - engaged in what is universally recognized as the "art" of translation. There is thus a kind of science/art tension/fusion at work from the beginning of his extended metaphor. Second, Quine's choice of the imaginary indigenous word for "rabbit," "Gavagai," is unnecessarily aesthetically pleasing - fun to say, with a lilting rhythm. Relatedly, his alternate descriptions and hypothetical translations of "Gavagai" are also unnecessarily lovely, from "momentary leporiform image," to "an otherwise 
rabbitless sequence," "rabbit-fly," "a stage of a rabbit," "an integral part of a rabbit," "the rabbit fusion," and "where rabbithood is manifested" (Quine 1960: 31, 37, 52-3). Third, in writing of "dispositions to assent," Quine suggests "positions" and "positing," which - as I have explored elsewhere - are connected to dance (via posing) and poetry (via poiesis as "positing" in Aristotle) of the theater (Quine 1960: 34). ${ }^{3}$ Fourth, although Quine speaks of the scientist being able to eventually "bicker with the native as a brother," neither Quine nor his commentators attach significant to the issue of being bilingual, which I wish to explore below (Quine 1960: 47, 74). Fifth, Quine writes that the "method of analytical hypotheses is a way of catapulting oneself into the native language by the momentum of the home language," and the necessarily approximate nature of catapulting is another good example of an art/science hybrid (Quine 1960: 70).

To clarify these points further, it may be instructive to compare the post-Quine development of the radical translation issue by Hilary Putnam in Meaning and the Moral Sciences. The main points I wish to emphasize from the latter book are that (a) Putnam uses artificial and alien lifeforms (namely a computer that produces speech patterns and the Martian interpreters thereof), rather than a fellow human society (as Quine does), and that (b) this correlates with Putnam's more counterproductively rigid metaphysical position there (in contrast to Quine's floe/flow metaphysics) (Quine 1960: 38).

The most important point to come out of this discussion in Putnam, as noted by (among others) Rorty, is Putnam's notion of “the 'interest-relativity' of explanation" (Putnam 1978: 41; Rorty 2009: 26). Putnam illustrates this with the example of the pointlessness of explaining - at a subatomic level - why a square peg will not fit in a round hole (Putnam 1978: 42). In making this point, Putnam explicitly acknowledges his pragmatist commitments, noting that he views "philosophy of science as normative description of science," which entails that "explanation has to be partly a pragmatic concept" (Putnam 1978: 42). Returning to the connection to his fellow Pragmatist, Putnam then modifies Quine's "Gavagai" thought experiment by, first, imagining two alternate translation manuals, using "rabbit" and "undetached rabbit-part," respectively (Putnam 1978: 44). Putnam uses this to extend Quine's "indeterminacy of translation" to what Putnam terms "an indeterminacy of reference" (Putnam 1978: 45). This second translation manual, and this is the key, is geared toward the relative interests of the Martians, who (due in part to their potentially smaller size relative to humans) find descriptions of "undetached rabbit parts" more natural, useful, intuitive, etc. than descriptions of "rabbits."

The gist of this modification by Putnam, for my purposes here, is that it attempts to undermine Quine's conception of the indeterminacy of translation by couching the latter within the determinacy of the biological makeup of the translators. In other words, compared to the interspecies translations between Martians and humans, the intercultural translations between the Western anthropologist and jungle tribal member appear to rest on a fairly secure basis after all. But the cost of this move for Putnam is that of leaving behind the only species we know scientifically to engage in translation, and to abandon that firmer ground for the imaginary realms of intelligent Martians. In this way, Putnam moves simultaneously (a) away from reality by positing a supercomputer and Martians, and (b) toward a static, reified, hyper-solid metaphysics. Quine, by contrast, sticks with humans, and stays in a floe-flowing middle path.

In other words, Putnam is only able to make intercultural translation seem reliable by contrasting intercultural translation with fictional translation involving a computer that we have been unable to design and an alien species that does not in fact inhabit the 
planet Mars. And the reason Putnam needs intercultural translation to be reliable is because the source of that reliability is the solidity and fixity of a mind-independent objective world of things, about which different cultures (and more importantly, different scientists) may communicate. Put differently, a close observation of actual human translation (as offered by Quine) reveals it to be much more fluid and creative than commonsense takes it to be. And the only way to save commonsense (as attempted by Putnam) is to depart even further from it and toward the realm of pure fiction and speculation. That is, Quine shows the seemingly ordinary to be a creative, imaginative endeavor in this world, while Putnam can only shore up the ordinariness of the ordinary by pretending temporarily to believe in something extraordinary but nonexistent.

I turn now from these additional considerations inspired by Word and Object's Preface to Chapter One. My translation of the content thereof will be that human dramatic virtuosity - including work in logic - turns on the following six primacies (or instances of prioritization or positing): (1) physical objects, (2) science, (3) sociality, (4) chaos, (5) simplicity and (6) familiarity. These six primacies can also be understood as constituting a preview of the results of Quine's subsequent investigation, and (more importantly for my article) as the six pillars of Quine's neo-Pragmatism.

17 First, Quine maintains that the first and most important things are physical objects, and for the following reasons: "Linguistically, and hence conceptually, the things in sharpest focus are the things that are public enough to be talked of publicly, common and conspicuous enough to be talked of often, and near enough to sense to be quickly identified and learned by name" (Quine 1960: 1). Physical objects come first because they are public, common and near-to-the-senses.

18 Contrarily, with regard to what has tended to dominate the materialists' ontology, "Talk of subjective sense qualities comes mainly as a derivative idiom" (Quine 1960: 1). Like a good Pragmatist-Aristotelian, Quine maintains that qualities inhere in substances; substances are not merely aggregates of qualities. Contrarily again, this time contrary to the liquefied end of the Pragmatist metaphysics spectrum, "immediate experience simply will not, of itself, cohere as an autonomous domain. References to physical things are largely what hold it together" (Quine 1960: 2). Physical objects are more coherent, more conceptualizable, than the pure flux or immediacy of experience. Quine thus makes use of a pragmatic principle to reject positions in the neighborhood of Rorty and James.

But what of the past? Those on the contrary side, which is to say the idealist side, of the Pragmatist spectrum of metaphysical systems (such as Brandom and Habermas), find the memory of past events an essential part of reality, and one that undermines the primacy of the physical objects currently in front of us. "[P]ast sense data," writes Quine (1960: 2-3), "are mostly gone for good except as commemorated in physical posits." The past is only real as embodied in current relations to physical objects, and those relations are merely relations of positing. And, what is even worse for the dignity of the long-ago, "a memory trace of a sense datum is too meager an affair to do much good. Actual memories mostly are traces not of past sensations but of past conceptualization or verbalization" (Quine 1960: 3). Here one finds an unexpectedly Proustian conceptuality of the past. Memories are not records of past truths, but are present fictions (poetically suspect interpretations) at work on past fictions. Again, all that one is left to rely on is the brute immediacy of one's stimulations, interpreted by recourse to the true fictitious positing of physical objects. 
20 Science, which is second among these six primacies, Quine (1960: 4) defines as "selfconscious common sense." This is science's ontology, and its language (its neologisms), correspondingly, are "just linguistic evolution gone self-conscious" (Quine 1960: 4). Science is the becoming-aware of language, the coming to awareness of a fundamentally dynamic and evolving phenomenon. But this self-conscious evolution, like its unselfconscious basis, is smooth and gradual, not jarringly abrupt. As Quine remarks (1960: 4), "we warp usage gradually enough to avoid rupture." Warping is thus the kind of poetic distortion, the kind of dramatic translation, native to science. Borrowing Wittgenstein's famous metaphor, Quine (1960: 4) suggests that, "we may kick away our ladder only after we have climbed it." Again one finds (this time Wittgensteinian) Pragmatism at the conclusion of Quine's analyses.

21 Quine then explicates this position as follows: "No inquiry being possible without some conceptual scheme, we may as well retain and use the best one we know - right down to the latest detail of quantum mechanics, if we know it and it matters" (Quine 1960: 4). As if the theater of life were not already uncertain enough, one now finds that the stage is not really a stage, that where the wooden planks of the floor would be, there are instead a plethora of wooden ladders, each supporting various actors who cling to them, and occasionally climb or jump from one ladder to another, kicking away the ones no longer needed, but always holding on to at least one. "Analyze theory-building how we will, we all must start in the middle" (Quine 1960: 4). Every actor is on a ladder, and no one can see how far down the ladders go, or where their base is, if there is any base at all. This reference to Wittgenstein and this concession to Pragmatism at the conclusion of Quine's analysis raise the question as to how all of this analysis of science relates back to philosophy.

"[P]hilosophy in turn," writes Quine (1960: 4), "as an effort to get clearer on things, is not to be distinguished in essential points of purpose and method from good and bad science." Therefore, by logical replacement of identical terms, one could characterize philosophy, too, as self-conscious commonsense; its terminology, too, as the product of self-conscious linguistic evolution; its method, too, as a poetic distortion of reality; and its governing principle, too, as that of James' pragmatic conception of truth - namely, "do what works."

Quine's third primacy is sociality. "Society, acting solely on overt manifestations, has been able to train the individual to say the socially proper thing in response even to socially undetectable stimulations" (Quine 1960: 5). In other words, the social cues that determine our linguistic behaviors are so powerful that each fully-trained actor reacts to the cues even when those cues are imperceptible to the others. Fortunately, as an actor, one moves beyond this automatic, robotically-programmed linguistic behavior, which Quine renders poetically as the "the fancifully fancyless medium of unvarnished news" (Quine 1960: 10). One moves beyond such behavior, specifically, because it is not in a human being's dramatic nature to rest with prosaic reporting, with knee-jerk responses. "We cannot rest," Quine (1960: 10) adds, "with a running conceptualization of the unsullied stream of experience; what we need is a sullying of the stream." The difference suggested in this last quote is between an attempt at automatic, faithful, factual recordings of experience, on the one hand, and intentionally strategic, poetic creations of experience, on the other. This creation of experience is a community activity, extending to each person, as both a society-created member and also a society-creating member of society. It is a view of human beings as essentially artist-scientists. 
Underneath language as social ordering, it turns out, lies a more fundamental chaos, and this chaos is Quine's fourth primacy. "Beneath the uniformity that unites us in communication there is a chaotic personal diversity of connections, and, for each of us, the connections continue to evolve. Not two of us ever learn our language alike, nor, in a sense, does any finish learning it while he lives" (Quine 1960: 13). Various actors have lines in common, but are they thinking and feeling the same things when they deliver those lines? Their different dramatic renditions would suggest that there are differences in thought, feeling, intent, purpose, etc., but there is, again, no objective measure by which to confirm that seeming.

Even the building blocks of these linguistic behaviors, according to Quine, are less clearcut and more chaotic than one tends to imagine. "What counts as a word, as against a string of two or more, is less evident" according to Quine (1960: 13) "than what counts as a sentence." It is only where words are distorted into sentences that one has greater clarity. "In the case of words it is a contrast between learning a word in isolation - i.e., in effect, as a one-word sentence - and learning it contextually, or by abstraction, as a fragment of sentences learned as wholes" (Quine 1960: 14). Naturally, the first strategy works better for concrete words, especially for physical objects, while the second strategy is necessary for abstract words, and there is a hierarchy for the two.

"What makes insensible [abstract] things intelligibly describable," Quine (1960: 14) continues, "is analogy, notably the special form of analogy known as extrapolation." One distorts one's concepts of physical objects into abstract concepts; one extrapolates physical objects into abstractions; and the physical basis is that to which everything returns. Words "mean only as their use in sentences is conditioned to sensory stimuli, verbal and otherwise" (Quine 1960: 17). These sentences, in turn, as sonic phenomena, are also sensory stimuli, which means that they too are capable of making words mean - a phenomenon that Quine poetically renders as "the interanimation of sentences" (Quine 1960: 18).

Quine's fifth principle, simplicity, is the one that is always at work resolving this chaos into the order previously considered. Considerations of simplicity, he explains, "in some sense may be said to determine even the least inquisitive observer's most casual acts of individual recognition" (Quine 1960: 19). Simplicity is therefore not one principle among many, or one that operates on occasion, but the governing principle of order, and one that is constantly in process. As Quine (1960: 19) puts it, "a law of least action remains prominent among [the observer's] guiding principles." philosophy. First, "Observation serves to test hypotheses after adoption; simplicity prompts their adoption for testing" (Quine 1960: 19). Observation only becomes relevant for hypotheses initially adopted on conceptually economic grounds. Second, the power of simplicity boosts the power of the hypotheses that it chooses by making it more extensive in its applications. "One incidental benefit of simplicity that can escape notice is that it tends to enhance a theory's scope - its richness in observable consequences" (Quine 1960: 20). Third, simplicity helps keep any given theory alive to its connections to other theories and to the fundamental nexus of practice/reality. The "simpler a theory, the more easily we can keep relevant considerations in mind" (Quine 1960: 20).

Quine's sixth and final primacy is a natural and logical consequence of simplicity, namely familiarity. "Familiarity of principle," he claims, "is what we are after when we contrive 
to 'explain' new matters by old laws" (Quine 1960: 20). Going with what is familiar is a way of simplifying things, and it guides us in the process of extrapolation from physical things to abstract things, from abstraction to abstraction, and even from physical reactions to physical objects. "Considered relative to our surface irritations," Quine (1960: 22) continues, "which exhaust our clues to an external world, the molecules and their extraordinary ilk are thus much on a par with the most ordinary physical objects." In other words, our method of creating abstract object such as molecules is not different in kind from our "creating" physical objects from an aggregation of physical responses to physical stimuli.

Quine then summarizes these six primacies. First, "What reality is like is the business of scientists, in the broadest sense, painstakingly to surmise" (Quine 1960: 22, emphasis added). Quine distorts artists, poets and even people in general into scientists. Second, "surmising what reality is like" is ultimately an artistic, groundless activity, not one that admits of indubitable "scientific" progress (Quine 1960: 22). We "have no reason," he claims, "to suppose that man's surface irritations even unto eternity admit of any one systematization that is scientifically better or simpler than all possible others" (Quine 1960: 22). (Notice also how closely Quine links "better" to "simpler.") "Scientific method," next, "is the way to truth, but it affords even in principle no unique definition of truth" (Quine 1960: 22). And even Pragmatism's truth fares no better in this indeterminate process, since any "so-called pragmatic definition of truth" for Quine "is doomed to failure equally" (Quine 1960: 23).

The bottom line, or "saving consideration," for Quine (1960:24) is that "we continue to take seriously our own particular aggregate science, our own particular work-theory or loose total fabric of quasi-theories, whatever it may be." In other words, all we have is our poetry, and that based on the social poetry of previous generations, but we all agree to believe in it, to pretend that it is not poetry, and so we all get along for the most part and get by.

32 I now turn from Word and Object to two other brief pieces by Quine, in order to buttress my interpretation of him as a neo-Pragmatist. Beginning with "The Pragmatists' Place in Empiricism," it begins with insults to the label "pragmatist," and then chalks up whatever is good in thinkers labeled as such to "empiricism." The rest of the essay is a list of the five improvements that empiricism has undergone, accompanied by the (so-called) Pragmatists' relationship to those five points. The points are as follows: (1) "the shift from ideas to words," (2) "the shift of semantic focus from terms to sentences," (3) "the shift of semantic focus from sentences to systems of sentences," (4) "abandonment of the analytic-synthetic dualism," and (5) "naturalism" (Quine 1981: 24).

33 As for the Pragmatists' relationship to these points, Quine's evaluation is distinctly ambivalent toward all the classical Pragmatists. For example, he mocks James for his "notorious defense of wishful thinking," but then praises him (and Dewey) for being "decidedly naturalistic in their way of doing epistemology" (Quine 1981: 32, 35). Quine's most purely positive evaluation, surprisingly, is of F.C.S. Schiller. Specifically, Quine celebrates Schiller's "doctrine of 'postulation,' which had us believing whatever we wish were true until it proves trouble" - because, for Quine, "scientific theory is man-made" (Quine 1960: 32, 33). The Pragmatists' most original contribution according to Quine, however, can be traced to George Herbert Mead, via Mead's student Charles Morris. To wit, Morris "chose the word 'pragmatics' for the behavioral end of the study of language" (Quine 1960: 37). Quine describes this innovation, along with "the doctrine of man as 
truth-maker," as his "two best guesses" as to the "shared and distinctive tenets" of Pragmatism, in which orbit he squarely places himself.

As for the implications for Quine's status as a neo-Pragmatist, counter-intuitively, it is this very ambivalence about pragmatism that most closely identifies him with it. One has only to think of any of the three classic Pragmatists to notice that all had tortured relationships with pragmatism. James popularized one view using its name, which prompted Peirce to abandon that name for a modified version thereof, and Dewey explicitly preferred other labels despite his obvious debts to, and sympathies with, Pragmatism's two founders. That is to say, it appears to me that a thinker's willingness and ability to recognize fluidity and differences within other thinkers labeled as Pragmatist, rather than condemning them wholesale via some caricatured oversimplification, constitutes positive evidence of pragmatism in that thinker. In short, a Pragmatist is someone who approaches other Pragmatists pragmatically. And this is exactly what Quine demonstrates here.

Turning to the second brief text from Quine, his "Reply to Morton," one can find pragmatism as well in Quine's rejection of Morton's attempt to make "emotions" a separate source (along with "sensations") of verification of Quine's "observation sentences" (Quine 1987: 663). Quine rejects this suggestion in a way that, at first, seems to denigrate the emotions. That is, he disqualifies them from serving as corroborators of observation sentences, on the grounds that they require too much "collateral" information (in addition to the present stimulus). In other words, sensation can produce unanimous assent or dissent in the moment, whereas emotion requires much past information as well. But this, ultimately, is a clue to Quine's pragmatist truth, which is that at least one value (namely truth) into which the emotions tap is part of the warp and woof of inquiry itself. Thus, "normative epistemology is a branch of engineering. It is the technology of truth-making" (Quine 1987: 664-5).

Put differently, value cannot serve in the infantry of inquiry (alongside sensations with observation sentences), because it is inquiry's general. Truth-seeking constitutes the spiritual cables that suspend disciplined knowledge above the turbulent waters of a world in flux - not because truth-seeking - and for Quine, this always means truth-making as well - is mixed into inquiry, but because inquiry's truth-directedness means that its fibers are always-already truth-oriented, and thus (at least in that respect) always-already ethical. And on this note of truth-making-seeking, I now turn to Mercer.

\section{Oh [Philosophically] Inverted World!}

37 In this section, I will consider the poem that is the first song from The Shins' first album, Oh, Inverted World! - "Caring is Creepy." I will analyze this poem using the Quinian neoPragmatism elaborated in my previous section. What emerges from this analysis will be a performance of philosophy as freaking out in the face of life, in the wake of which one moves toward a Pragmatist acceptiance of the semi-stable ice floe on the underlying flow of reality (or the theater as shelter of poetic constructions from the turbulent outside world). But first, I will preface my Quinian translation of "Caring is Creepy" with two broad considerations about Mercer's work.

First, Mercer's poems (qua the lyrics to The Shins' songs) exist primarily as technological recordings of popular music, played sometimes on the radio but more often on $\mathrm{CD}$ 
players, MP3 players, etc. These are his poetry's primary media, and they are performative and repetitive ones. Relating this back to the overarching trope of my article, logical theatrics, one could say that the radio, CD player and MP3 player are all in a way personal theaters, and that when played on them, The Shins' music constitutes a kind of private theatrics. This extension of the theater into the home and for private use is of course a logical extension of Western technological virtuosity. It makes sense that music, along with the rest of Western culture, would be subjected to technological production and commodification.

Secondly, as a preview of "Caring is Creepy," and for a concise demonstration of Mercer's resonance with Quine, consider the following passage from "Fighting in a Sack," from the Shins' second album, Chutes Too Narrow: "to keep this boat afloat well there are things you can't afford to know so I save all my breath for the sails." The metaphor for society here, a boat, is a structure built for locomotion, not a secure dwelling on a permanent ground, which suggests the chaotic basis of Quine's human world (and the floe/flow metaphor for Quine's moderate Pragmatist metaphysics). The passage also suggests that certain truths about this world need to be ignored, that we improvise in order to distort away certain things on a dramatic scale, echoing Quine's translation as distortion. Finally, the motive that the passage attributes to these distortions is a thoroughly practical one, entirely sympathetic with Quine's neo-Pragmatism. We seek to keep the boat afloat in the chaotic seas, so we distort our knowledge of the world, and save our energies for that which keeps our boat sailing along. Here, in just one sentence, the Shins articulate Quine's (a) chaotic basis, (b) method of distortion and (c) moderate Pragmatist metaphysics. The title of the primary song under consideration, "Caring is Creepy," could be referencing the fact that one of the arguably most pervasive of all human emotions, namely care, has come to seem unnatural. This discomfort with emotionality is a commonly criticized trend in much traditional Western philosophy; it has frequently been alleged (by Wittgenstein among others) that philosophy constitutes a semi-willing self-alienation from life out of a fear of its inevitable uncertainties and pains. In other words, one could translate philosophy into a being "freaked out" in the face of life.

The orientation of the poem (that is, as song lyrics), insofar as the poem is written in first person and addresses an informal "you," works much like the monologue of dramatic poetry such as Shakespeare's plays. This conception of dramatic monologue also resonates with the dramatic elements of Quine's Word and Object, in which the "natives" and Western "jungle linguist" play vital performative roles, and according to which reference can only be established and clarified through translation - by the trespassing from one speaker to another, whether between or within a human body.

I now proceed to a consideration of the entire poem, line by line.

"I think I'll go home and mull this over"

The song begins with the subject I, the ego, reflecting on the fact that it is about to begin reflecting. The verb here, according to the American Heritage College Dictionary, is etymologically derived from "[prob. ME moillen, mullen, to moisten, crumble]." Another denotation it lists for "mull" is "to heat and spice (wine, for example)" (895). Thinking in English is thus a kind of heating, spicing, moistening and crumbling. And philosophy is nothing if not reflecting.

"before I cram it down my throat" 
Presumably unintentionally, Mercer stays true to the Middle English referent of "mull" with the song's first bit of colorful phrasing. After moistening and crumbling whatever "it" is (we never find out for sure), the speaker intends to cram it down his throat. This line also resonates with Quine's colorful description of his hypothetical bilingual "jungle linguist" who "deals observably with the native informant as live collaborator rather than first ingesting him" (Quine 1960: 71). One imagines that Quine would applaud the speaker's plans for some pre-digestion rumination.

"at long last it's crashed, the colossal mass

has broken up into bits in my moat."

Notice, still from "mull," the crumbling that happens to the colossal mass. I would argue that this couplet refers to the confrontation between the universality of ideas and the particularity of the contemplator, necessitating the dramatic change in the universal "substance" for it to be absorbed by the particular speaker of the poem.

"lift the mattress off the floor"

Here the mattress, essential equipment for sleep, is lifted out of its place. The possibility for sleep is denied to someone whose mattress was already not in the place most conducive to restful sleeping, a bed. Physicality is pushed back for the colossal mass of abstract reflection. Similar neglecting of physicality is one of the defining features of Quine's analytic brethren (at least from the perspective of many of their critics).

"walk the cramps off"

The thinker's body has been neglected for the sake of thought, so much so that the muscles have begun to cramp from atrophy. Philosophically exercising the muscles of the brain is not sufficient to prevent cramping.

"go meander in the cold"

When physicality is finally allowed to occur, in the walking, it immediately becomes a meandering, "mov[ing] aimlessly and idly without fixed direction," motion disconnected from practical purpose. The speaker encourages someone to move around like the speaker thinks: aimlessly and idly, and in the cold, in an atmosphere devoid of warmth warmth being the totem state of healthy mammalian physicality.

"hail to your dark skin"

The ratiocinating speaker of the poem draws attention, for the first time, to a descriptive quality of the person being addressed - dark skin - which summons connotations of the imperialist white male (as the lead singer, Mercer, is in fact a white male) addressing subaltern populations of color. This also reminds one of the discriminatory connotations of Quine's figure of the "primitive jungle natives."

"hiding the fact you're dead again"

Death is perhaps the most enduring gift of the white Western male to the black Eastern female. For writing and rationality, à la Derrida, are always directed to death. And though "a hero dies once," as the saying goes, "the coward [philosopher] dies many times in one lifetime."

"underneath the power lines seeking shade

far above our heads are the icy heights that contain all reason"

In the first of these two lines, the ineffectualness of refuge from the burning eye of Reason is invoked, or the non-consolation of traditional Western philosophy, lines of power channeling surging currents, and too thin to protect something like skin from something like excessive sunshine. 
In the second line, perhaps, is the song's climax. The abstract objects of traditional Western philosophical rationality are always-already out of our reach and cold from lifelessness.

"it's a luscious mix of words and tricks

that let us bet when you know we should fold"

Notice the change here in from philosophical critique of philosophy to philosophical solution to philosophy, from diagnosis to prognosis and prognostication. Poetry and Pragmatism, unlike traditional Western philosophy, make life possible, although they do so through somewhat obvious tricks of aestheticizing and conceding to (basely) practical motives. The result: a Jamesian betting on life once more, an existential commitment, based on the beauty of the way things sound the world.

"on rocks I dreamt of where we'd stepped"

54 Having foregone the mattress, the speaker has taken to sleeping on that most uncomfortable of human sleeping surfaces: rocks. Or perhaps s/he just dreams awake. Either way, s/he dreams about stepping, and thus about walking, and dynamic physicality.

"and of the whole mess of roads we're now on."

Things have gotten tangled since the stepping started. But life is like that, full of tangles.

"hold your glass up, hold it in"

The truth in wine, the pervasiveness of repression, respectively.

"never betray the way you've always known it is."

Stick to your irrational upbringing, your instincts, the principles that defend you from thought, doubt and despair. With Quine, all theory is theorizing-in-the-middle and doingthe-best-we-can-with-what-we've-got, because, after all, what else can we do?

"one day I'll be wondering how"

It begins in wonder, said Aristotle.

"I got so old just wondering how"

It ends in wondering about wonder, about its beginnings, the poem's speaker adds. Reality may be circular, but one's hair turns gray only once, and before one dies. Philosophy has made the speaker of the poem almost die from getting old wondering.

"I never got cold wearing nothing in the snow."

Traditional Western philosophy and its rationality find life irrelevant. They don't notice the cold, perhaps because their natural element is abstract frigidity?

"this is way beyond my remote concern"

Apathy: the emotion of traditional Western philosophy as practiced, for example among the Stoics.

"of being condescending"

Elitism: the hallmark of traditional Western philosophers as practitioners, for example in Plato and Aristotle's aristocratic tendencies.

"all these squawking birds won't quit."

The philosophers do tend, one must admit, to go on for thousands of pages.

"building nothing, laying bricks."

All the philosophers "lay" (because historically it is neither many sexual partners, nor bricks for a house) are metaphorical pieces of excrement. 
to meanings," (Quine 1980: 12) and Mercer writes of being "allergic to love" ("Know Your Onion!"). In both cases, the rejection of an abstraction is figured in reductively physiological terms; that is, rejection of an idea is a matter of the body's rejecting it naturalism triumphs.

71 Secondly, "Two Dogmas of Empiricism" offers the following two interesting moments of alliance: (a) Quine claims that "judgment turned out to be a will-o-the-wisp," (Quine 1980, 32) while Mercer rights of "too many good intentions / held by clever sprites" ("Red 
Rabbits"); and (b) Quine refers to a "metaphysical article of faith," (Quine 1980, 37) while Mercer writes that "though the saints dub us divine in ancient fading lines / Their sentiment is just as hard to pick from the vine" ("Saint Simon").

Third, "Logic and the Reification of Universals" includes the following three moments: (a) "a torrent of universals against which intuition is powerless" (Quine 1980: 123) comparable to "ideas that can't help / but creep good people out" ("Pressed in a Book"); (b) the mathematical conceptualist as "squeamish" (Quine 1980: 127) comparable to "Most ideas turn to dust / As there are few in which we all can trust / Haven't you noticed I've been shedding all of mine?" ("Fighting in a Sack"); and (c) the mathematical nominalist easing his "puritanic conscience" by comparing himself to the "lotus-eating" Platonists (Quine 1980: 129) comparable to "You are not some saint who's above, / Giving someone a stroll through the flowers" ("Girl Sailor").

Fourth, "Reference and Modality" notes that "nonsense" "can always be remedied by arbitrarily assigning some sense," (Quine 1980: 150) while Mercer writes of "the nursery rhymes that helped us out in making sense of our lives" ("Saint Simon").

And finally, "Meaning and Inference" claims that logic "presumed to a certain degree of creativity," but that its artifice "is a good one," comparable to the following lines from "A Comet Appears" in conjunction with the subsequent lines from "Young Pilgrims" and "Sleeping Lessons":

Every post you can hitch your faith on

Is a pie in the sky

Chock full of lies,

A tool we devise,

To make sinking stones fly

of course I was raised to gather courage from those

Lofty tales so tried and true and

If you're able I'd suggest it 'cause this

Modern thought can get the best of you.

And if the old guards still defend,

They got nothing left on which you depend,

So enlist every ounce of your bright blood,

And off with their heads.

Jump from the book,

You're not obliged to swallow anything you despise,

75 Altogether then, Mercer's poems rearticulate (in their own idiom) Quine's insights that (a) our ideas are pragmatic fictions, which are (b) good and worthy as long as they serve our pragmatic purposes, and thus (c) prudent to abandon and replace when they no longer thus serve.

Returning to Quine's “The Pragmatists' Place in Empiricism," both the five points in the evolution of empiricism, and also the reasons for Quine's self-identification as a Pragmatist, align nicely with Mercer as well. The five points align as follows,

(1) Mercer affirms "words" over "ideas," noting the "impact" of the former and their useful combination with "tricks" (while ideas "creep good people out," "turn to dust," and are "vague" and un-relatable). (2) Most of the individual words in the lyrics are literally meaningless outside of their context in the lines and sentences of the songs. (3) Similarly, most of the lines and sentences are meaningless outside of the entire songs, of the songs that make up an entire album, and even of their entire four-album oeuvre. (4) Mercer mocks a priori truth claims (the "icy heights that contain all reason") in favor of 
empirical investigation, ("Under the rocks are snails and we can fills our pockets / And let them go one by one all day in a brand new place"). And (5) as Mercer writes, "the trick is just making yourself."

As for Quine's self-identification as Pragmatist, consider the following lines from Mercer's "Port of Morrow" (title track from The Shins' latest album):

Under my hat it reads

The lines are all imagined.

A fact of life

I know

To hide from my little girls.

I know my place amongst

The bugs and all the animals.

That is, like Quine, Mercer simultaneously affirms (a) truth as human-made/imagined, and (b) the objective truth or reality of that making, the pragmatic implication of which is to remember his objective place in the naturalistic world of the animal kingdom.

Finally in terms of supporting evidence for Quine and Mercer's singular compatibility, there are significant isomorphisms of style between Quine and Mercer. For example, if one combs carefully through all four of The Shins' studio albums, the following four patterns emerge. First, in sympathy with Quine's allusions to Neurath's bootstrap (which compares language to a ship that can only be repaired at sea), there are five references to "boats" in a similar tenor (including "turn this ancient boat around," "keep this boat afloat," "if your're a seascape I'm a listing boat," "an emptier boat" and "an upturned boat"), thirteen references to the "sea," and four to the "ocean." Moreover, there is a marked preference for the sea as a means of travel compared to the sky (where everything is unreachable, and ends up crashing anyway). Second, in terms of Quine's famous "Gavagai"/rabbit example, there are five instances of the word "rabbit" in the songs. Third, Mercer shares Quine's fixation on math, including references in the songs to "multiplying," "quotients," "algebra," "adding it up," "subtraction," geometric "lines dissecting love," and "measuring," as well as multiple references to numbers abstracted from any concrete context. Finally, both Quine and Mercer engage in effective and enjoyable self-deprecating humor (including being "allergic" to meanings/love respectively).

\section{Theatrical Flowing Conclusion}

81 To summarize the above analyses, by "logical theatrics," I mean the following: (1) theatrics which follow logically (i.e., from the nature of reality); (2) theatrics inherent in/ as the nature of logic; (3) logic as the sub-discipline of philosophy; (4) logic as the transcendental law of thought; (5) logic as logos as discourse; (6) theatrics as the essence of the theater; (7) theatrics as over-dramatic human behavior; and (8) theatrics as human nature qua dramatic. Quine's discourse, on these terms, is a theatrically-accented discourse about the necessary theatrics of logic as it enacts the theater of the world. Mercer's discourse, on the same terms, is a theatrically based logic of reality as the drama of discourse. Quine's thought is a logical consequent of the theatrical world, while Mercer's thought is the chronologically logical theatrics of Quine's logic, and mine is the logical and over-dramatically theatrical blending of these logical theatrics and theatrical logics. 
82 sheltered against the historical evolution of society. To follow in the roles of Quine and his commentators, one could picture this as a variation on the "Gavagai" translation script. My own attempt in the present article could thus be understood as a new, triadic translation, namely between Quinian, Mercerian, and my own language, which one might call "Reconstructish," the language of we who live in the tumultuous wake of Rorty's big three (Dewey, Heidegger and Wittgenstein) and their followers (including Rorty himself). ${ }^{4}$ That is, instead of merely translating a new indigenous language into one's own (like Quine's anthropologist), I have attempted to translate two different languages into a third for the benefit of the speakers of the latter and the rest of our shared globe. recourse to the aforementioned Neurath's bootstrap, in that the "ship of self" (Mercer) and the "ship of science" (Quine) must be repaired "at sea." To contextualize this point in relation to the variety of contemporary Pragmatist metaphysics and philosophies of language, Quine and Mercer make logic flow, not all the way to liquefying it, but rather like an ice floe, a sheet of ice floating on the water beneath. The floe and the flow are of the same watery substance, and any molecule above could just as well have been (or become) a molecule beneath; but one can travel on the floe because the current arrangement is stable enough as it is. This, then, is what makes Mercer and Quine singularly suited for each other. They both posit that a reality understood as posited is enough to have something worthy of the word reality. And in so doing, they offer a Pragmatist middle way between Pragmatist total liquefying (as in Rorty's conversation melted to pure whimsy) and Pragmatist total freezing (as in Habermas' conversation reified into scientific object).

Although I am merely a humble translator, whose own sympathies lie more (like Bernstein) with Dewey and Mead (and who is most at home speaking Reconstructish) I can step back from philosophical partisanship and look in a naturalistic spirit to two contemporary issues in regard to which Quine/Mercer's position has much to offer. To wit, (a) the literal ice on our waters, such as the polar ice caps, are melting into undifferentiated ocean as part of the tragedy of global climate change, and (b) our poetry and theaters are disappearing into the flow of mass market culture and cinema. The connection I find is that Quine and the Shins help pull us back from both total liquidizing and elitist rigor mortis - keeping the theater inside the world, our floe navigable on the flow. Put differently, we cannot survive in undifferentiated water without a handhold or a place to rest our bodies, nor can we survive of dehydration in castles of unyielding ice. Similarly, no livable world can be reified into, à la Shakespeare, "but a stage" (as suggested by, among other things, so-called "reality" television), nor is life worth living in a world where all vestige of the shelter of the theater and poetry have been liquidated into consumer consumption.

To return again to my titular metaphor, the present article has attempted to stage a new encounter between Quine and Mercer for the audience of my readers. The upshot of this performance is that, for Quine and Mercer, we need neither a reduction of structure to pure logic-less mess, nor a special elevating of one narrative (physics for Quine, perhaps elegy for Mercer?), but rather a pragmatic humbling of science and an elevation of art into a new fusion: a stable, disciplined Wissenshaftkunst - a Nietzschean "gay science" of poetry. Armed with this scientific art, perhaps more Anglo-American philosophers can be persuaded to abandon their ice castles and join our Reconstructish sea-battle - using

European Journal of Pragmatism and American Philosophy, VIII-2 | 2016 
logical creations strategically to save the arts (including the theater and poetry) and even the Earth itself (from global climate change). ${ }^{5}$

Less ambitiously, one might hope that Quine translated as a moderate, neo-Pragmatist metaphysician can do for Pragmatism (intra-Pragmatically) what Pragmatism does for Anglo-American philosophy (extra-Pragmatically), namely offer a persuasive style and rhetoric for those most tightly in the clutches of the kind of philosophical rigor mortis that dominates mainstream, ahistorical Anglo-American philosophy. Within Pragmatism itself, the symptoms of this are visible when Pragmatists such as Habermas talk about "facts" and "how things are." This is analogous to trying to fit the world into a theater that forgets its metaphysical origins and structure lie in artifice.

In any event, there is significant benefit to be had merely in noting that even someone like Quine, located in the middle of this Pragmatist metaphysical spectrum, can be translated effectively into the work of a popular poet such as Mercer. Moreover, this unholy alliance already begins to suggest Quine's own blending of the arts and sciences (and Mercer's frequent invocation of scientific fact in his poetry). Together, these two philosopher-poets marry aesthetically-rich scientific hypothesizing to scientificallydisciplined artistic creation. In short, Quine and Mercer help show us that beautiful science, rigorous art, and philosophy truly in the world can still save the latter. So let us take up our theatrical true logics, and join the good fight.

\section{BIBLIOGRAPHY}

BERNSTEIN R., (2010), The Pragmatic Turn, Cambridge, UK, Polity Press.

DAVIDSON D., (2005), “A Nice Derangement of Epitaphs,” Truth, Language and History, Oxford, Oxford University Press.

HALl M. Joshua, (forthcoming), “Positure in Plato's Laws: An Introduction to Figuration on Civic Education," Journal of Social Science Education.

PAGIN P., (2008), “Indeterminacy and the Analytic/Synthetic Distinctions: A Survey," Synthese 164, $1-18$.

PUTNAM H., (1978), Meaning and the Moral Sciences, London, Routledge.

QUINE W., (1960), Word and Object, Cambridge, MIT Press.

QUINE W., (1980), From a Logical Point of View: Nine Logico-Philosophical Essays, 2nd ed. Cambridge, Harvard University Press.

QUINE W., (1981), “'The Pragmatists’ Place in Empiricism,” Robert J. Mulvaney \& Philip M. Zeltner (eds.), Pragmatism: Its Sources and Prospects, Columbia, University of South Carolina Press, 21-40.

QUINE W., (1987), “Reply to Morton,” Lewis E. Hahn \& Paul A. Schilpp (eds.), The Philosophy of W. V. Quine. Lasalle, IL, Open Court, 663-8.

RAYO A., (2002), “Word and Objects," Noûs, 36, 3, 436-64. 
RORTY R., (2009), Philosophy and the mirror of nature, 30th anniversary ed. Princeton, Princeton University Press.

THE AMERICAN HERITAGE COLLEGE DICTIONARY, (1997), Boston, Houghton Mifflin.

THE SHINS, (2001), “Caring is Creepy," written by James Mercer, from the album Oh, Inverted World! Sub-Pop Records.

\section{NOTES}

1. For recent, more orthodox interpretations of Quine's Word and Object, see Pagin 2008, and Rayo 2002.

2. This position is based on Myers' undergraduate course entitled "Pragmatism," held at Birmingham-Southern College in the spring of 2003.

3. See Hall forthcoming.

4. The reader uncomfortable with thinking of Quine's oeuvre, or Mercer's (let alone my invention) as a language, should perhaps consult Davidson's "A Nice Derangement of Epitaphs," regarding his claim that there is no such thing as a "language" separate from the sum total of the sentences asserted by speakers thereof (Davidson 2005: 107).

5. This is where, I would argue, Rorty goes wrong in his analyses of Quine as a scientistic reductionist (for example, Rorty 2009: 155). To wit, Rorty equivocates between the following two dichotomies: (a) logic, math and "hard" science versus every other discourse, with (b) disciplined inquiry (inclusive of science, technology, the arts, etc.) versus disorganized experience. If Quine is interpreted as advocating (b) rather than (a), then he can understood as being on board with Rorty's own advocacy of disciplined inquiry in both the arts and sciences (for example, Rorty 2009: 339, 344-5).

\section{ABSTRACTS}

This article investigates a philosopher and a poet who initially appear to occupy opposing ends of the traditional spectrum from prosaic conceptuality to poetic immanence. The philosopher is twentieth century United States philosopher Willard Van Orman Quine, one of the central figures in the most prosaic tradition of the history of Western philosophy: so-called analytic or AngloAmerican philosophy. The poet is James Mercer, lead singer, guitarist and lyricist for the contemporary "Independent rock" band The Shins, and as such is intimately bound to that allegedly most shallow and unthinking type of all Western music: popular rock and roll. In brief, I will argue that both Quine and Mercer suggest a theatricality at the heart of logical thought and a logic of the theatrical - in other words, a logical theatrics. Or, to put it in terms of a spectrum of Pragmatist metaphysical positions (from pure process to naïve realism), Quine and Mercer offer neither a pure flux in which logic is dissolved, nor a timeless logic that freezes all life from the world, but rather an ice floe of logic on which to navigate the flows of experience. 


\section{AUTHOR}

JOSHUA M. HALL

CUNY, Queensborough

jhall[at]qcc.cuny.edu 